\title{
As relações das meninas com os saberes das lutas nas aulas de Educação Física
}

\author{
Marcos Roberto So \\ Mariana Zuaneti Martins² \\ Mauro Betti ${ }^{3}$
}

\section{RESUMO}

Com base na teoria da "relação com o saber" de Bernard Charlot, esta investigação teve como objetivo analisar as relações de sentido e a mobilização das meninas com os saberes das lutas. Para tanto, este estudo utilizou: (i) observação de aulas do conteúdo judô em uma turma do $7^{\circ}$ ano do Ensino Fundamental; e (ii) entrevistas semiestruturadas com 17 alunos da turma. Os resultados indicaram menor mobilização das meninas em comparação aos meninos. Os elementos desfavoráveis à mobilização feminina foram separados em três categorias: (i) a masculinização e o machismo na luta; (ii) o medo de se machucar; (iii) vergonha de se expor. Ressaltar as dificuldades do tema gênero e lutas não significa descartá-las do processo pedagógico, por isso, concluímos o artigo apontando a criação de experiências que subvertam e transgridam tais barreiras.

Palavras-chave: Lutas. Gênero. Mobilização feminina. Relação com o saber

1 Mestre em Educação. Professor do Instituto Federal do Sul de Minas Gerais (IFSULDEMINAS). Pouso Alegre/ Minas Gerais, Brasil. E-mail: marcos.so@ifsuldeminas.edu.br

2 Doutora em Educação Física. Professora Adjunto A da Universidade Federal do Espírito Santo (UFES). Vitória/ Espírito Santo, Brasil. E-mail: marianazuaneti@gmail.com

3 Doutorado em Educação. Livre-Docência pela Universidade Estadual Paulista (UNESP). Bauru/São Paulo, Brasil. E-mail: maurobettiunesp@gmail.com

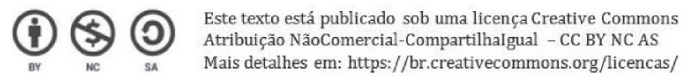


Relations of girls students to martial arts knowledge in Physical Education lessons

\begin{abstract}
Based on "relation to knowledge" theory of Bernard Charlot, the question of this investigation is: what are the relations of meaning and mobilization of girls with martial arts knowledge? This a qualitative study with the following procedures: lessons observation of judo content in a seventh grade class of Midle School; and semiestructured interviews with 17 class students. The results indicated less mobilization of girls in comparison to boys. The elements unfavorable to female mobilziation were separated into three categories: (i) masculinization and machismo in martial arts; (ii) the fear of being hurt; (iii) embarrassment to expose yourself. To conclude, is important to emphasize that difficulties of gender and martial arts does not mean discarding them from the pedagogical process, but rather encourages the creation of experiences that subvert and trangress such barries.
\end{abstract}

Keywords: Martial arts. Gender. Female mobilization. Relation to knowledge

Las relaciones de las ninãs con los saberes de las luchas en las clases de Educación Física

\title{
RESUMEN
}

Con base en la teoria de la "relación con el saber" de Bernard Charlot, esta investigación parte de la cuestión: ¿cuáles son las relaciones de sentido y movilización de las niñas con los saberes de las luchas? Se trata de un estudio cualitativo que utilizó: la observación de clases del contenido judo en una clase del $7^{\circ}$ año de enseñanza primaria; y entrevistas semiestructuradas con 17 alumnos de la clase. Los resultados indicaron menor movilizacíon de las niñas en comparación a los niños. Los elementos desfavorables a la movilización femenina se separaron en tres categorías: (i) la masculinización y el machismo en la lucha; (ii) el miedo de herirse; (iii) vergüenza de exponerse. Se concluye que resaltar las dificultades del tema género y luchas, no significa descartarlas del proceso pedagógico, sino de incentivar la creación de experiencias que subvierten y transgreden tales barreras.

Palavras chave: Luchas. Género. Movilización feminina. Relación con el saber 


\section{INTRODUÇÃO ${ }^{4}$}

Por detrás do universo "masculino" das lutas, é cada vez mais notório o aumento da participação de mulheres nesta prática corporal. Algumas situações reforçam este fenômeno de ocupação feminina em ambientes de lutas: a inclusão de mulheres em combates de MMA (Artes Marciais Mistas), transmissão televisa de lutas femininas e a criação de horários específicos para mulheres em academias que ensinam lutas. Outro elemento que reforça tais constatações é a produção recente de investigações que tematizam as relações de gênero e sexualidade nas lutas. Destacam-se os seguintes resultados: (i) a prática de distintas modalidades de lutas têm contribuído para a visibilidade da performatividade de feminilidades plurais (FERNANDES et al., 2015; FERNANDES; MOURÃO, 2014; SALVINI; JÚNIOR, 2016); (ii) os motivos das mulheres optarem pela prática de lutas relacionam-se com a melhoria de saúde e ao ganho estético, diferenciando-se de ritos e códigos tradicionais das lutas (SILVA et al, 2015); (iii) as mulheres preferem modalidades de lutas que hipertrofiam membros inferiores, como a capoeira, taekwondoo, etc (FERRETI, 2011); (iv) há uma necessidade das mulheres se masculinizarem para serem aceitas nas lutas (FERRETTI, 2011); (v) existe uma produção normativa do corpo da mulher que luta, como é o caso da criação da categoria peso galo no MMA feminino, com claros objetivos de enaltecer as supostas características de "mais femininas e sensuais" (SALVINI; JÚNIOR, 2016).

Todavia, no âmbito da Educação Física escolar, tais discussões relacionadas às lutas e o tema "gênero e sexualidade" pouco foram problematizadas. Vale ressaltar que em consulta em diversos periódicos nacionais ${ }^{5}$, utilizando-se as palavras-chave "luta" e "arte marcial", não foram encontrados estudos que relacionam, concomitantemente, os três temas a seguir: lutas, gênero e Educação Física escolar. Ou seja, as pesquisas da área ou indagam, como mencionado em linhas anteriores, sobre as problematizações de lutas e gênero; ou questões relativas a gênero e sexualidade nas aulas de Educação Física (por exemplo: ALTMANN, 1998; JESUS; DEVIDE, 2006; CHAN-VIANNA; MOURA; MOURÃO, 2010; WENETZ; STIGGER, 2006); ou investigações que inter-relacionam lutas e Educação Física escolar (por exemplo: NASCIMENTO; ALMEIDA, 2007; RUFINO; DARIDO, 2015). Portanto, o estudo das relações de gênero nas lutas da Educação Física escolar demonstra ser um campo fértil para se questionar: como decorre a participação das meninas no conteúdo lutas nas aulas de Educação Física? Quais seriam os motivos de participação ou não-participação nestas aulas? Quais os sentidos atribuídos pelas meninas?

Por gênero consideramos a organização da diferença socialmente percebida entre sexos, que é atravessada por relações de poder, constituindo desigualdades de oportunidades e de recursos para os gêneros (SCOTT, 1990). Ademais, podemos considerar que o

4 Declaramos que este trabalho não possui conflito de interesses.

5 Consultamos as bases de dados dos seguintes periódicos: Revista Brasileira de Ciência e Movimento, Revista Brasileira de Educação Física e Esportes, Revista Brasileira de Ciências do Esporte, Revista Conexões, Revista de Educação Física/UEM, Revista Mackenzie de Educação Física e esportes; Revista Motrivivência; Revista Motriz; Revista Movimento; Revista Pensar a prática 
comportamento do corpo sexuado, por mais rotinizado que seja, nem sempre se apresenta estável ou homogêneo, mas também pode ser "produzido e imposto por práticas reguladoras da coerência de gênero (...), [sendo] uma identidade [que] é performativamente construída, pelas próprias expressões tidas como seus resultados" (BUTLER, 2014, p. 48). Nesse sentido, não é possível excluir possibilidades de transgressões e de subversões em identidades flutuantes de gênero, como é o caso da inserção de mulheres, imbuídas de sentidos próprios, em uma "arena" considerada "masculina".

É possível inferir que esta ausência de estudos supracitada reflete a implementação recente das lutas na Educação Física escolar, que ainda encontra dificuldades quanto ao seu trato pedagógico, por alguns motivos: (i) baixa produção científica-acadêmica do tema lutas e Educação Física escolar (CORREIA; FRANCHINI, 2010); (ii) formação deficitária de professores (NASCIMENTO; ALMEIDA, 2007, RUFINO; DARIDO, 2015); (iii) dificuldade docente de construir conhecimentos específicos e pedagógicas das lutas (SO; BETTI, 2013).

Outra lacuna perceptível é a ausência de investigações que considerem e analisem a relação dos alunos com os saberes das lutas nas aulas de Educação Física. Vale complementar que mesmo os estudos no âmbito das perspectivas dos alunos sobre as aulas de Educação Física ainda são marcados por abordagens de caráter meramente descritivo, que carecem de um "quadro teórico mais consistente tanto para a geração dos dados como para sua interpretação". (BETTI; USHINOHANA, 2015, p. 5).

Nesse sentido, a atual investigação possui como base a "teoria da relação com o saber" de Charlot (2000, 2001), para quem aprender é um processo de apropriação de saberes "de uma humanidade, que lhe é 'exterior' [...] que exige mediação do outro" (CHARLOT, 2000, p.54). A ação pedagógica docente de ensinar (mediação do outro exterior) deve ir ao encontro de um "movimento interior discente", ou nas palavras do autor: "mobilização", que é reunir esforços próprios para iniciar algo. Porém, o sujeito que se mobiliza põe-se em movimento em uma atividade, que por sua vez, é compreendida como conjunto de ações desencadeadas a partir de um móbil com objetivo de alcançar uma meta, um fim. Entretanto, pelo caráter de infinitude, seria impossível o sujeito se mobilizar por todo patrimônio produzido pela humanidade, o que significa que o sujeito só se põe em movimento de maneira seletiva, para as coisas e saberes de interesse, ou nos termos do autor, de sentido.

Além dos elementos relativos à propulsão no sujeito - mobilização, atividade e sentido -, Charlot (2000) destaca três dimensões que também sustentam a teoria da relação com o saber: epistêmica, identitária e social. A dimensão epistêmica refere-se a natureza dos saberes. Não são os mesmos aprenderes quando se lida com: (i) expressões aritméticas, ler um livro e escrever uma produção textual de gênero e sexualidade (saber-objeto - conteúdo linguisticamente enunciado); (ii) aprendizagem do nado, do rolamento de judô (saber-domínio - consistem em dominar um objeto ou atividade); (iii) fazer amizades, enfrentar barreiras de gênero em um treino de alguma modalidade lutas, cumprimentar um colega nas aulas de judô.

A dimensão identitária faz referência à singularidade do sujeito. É a seletividade do sujeito, que por uma relação de valor e importância, seleciona algo para aprender que 
Ihe faça sentido, frente "às suas expectativas, às suas referências, à sua concepção de vida, às suas relações com os outros, à imagem que tem de si e à que quer dar de si aos outros" (CHARLOT, 2000, p.72).

Por fim, a dimensão social considera os condicionantes sociais como indutores de relações com os saberes presentes no mundo, por exemplo, nas aulas de Educação Física no Brasil, é mais provável uma menina entrar em contato com os saberes do futebol do que os do kung fu. Portanto, a escola também representa um "lugar que induz relações com os saberes" (CHARLOT, 2001, p.18).

Assim, o objetivo desta investigação é compreender, com base na "teoria da relação com o saber", como alunas se relacionam com os saberes das lutas nas aulas de EF. Isto é, como o marcador de gênero pode interferir na mobilização e participação de meninas no conteúdo lutas nas aulas de Educação Física escolar, levando em conta as seguintes questões: (i) quais as relações de sentido e qual a mobilização das meninas com os saberes das lutas? (ii) quais fatores interferem na mobilização feminina?; (iii) quais são os discursos generificados apresentados por alunas e alunos?

\section{PROCEDIMENTOS METODOLÓGICOS}

A atual investigação é um desdobramento de uma pesquisa maior que buscou analisar como discentes se relacionam com o conteúdo lutas nas aulas de EF. Trata-se de um estudo orientado pelo paradigma das pesquisas qualitativas em educação, o que implica em uma imersão escolar, em estar "dentro" da sala de aula, do projeto educativo (STENHOUSE, 1993). Por dados qualitativos entende-se:

Descrições detalhadas de situações, eventos, pessoas, interações e comportamentos observados; citações literais do que as pessoas falam sobre suas experiências, atitudes, crenças e pensamentos; trechos ou íntegras de documentos, correspondências, atas ou relatórios de casos (PATTON apud ALVES-MAZZOTTI, 1999, p. 132).

Especificamente, foi realizado um estudo de caso, conforme Alves-Mazzotti (2006, p.650): "investigação de uma unidade específica, situada em seu contexto, selecionada segundo critérios predeterminados e utilizando múltiplas fontes de dados, que se propõe a oferecer uma visão holística do fenômeno estudado". O estudo de caso não busca apenas compreender o caso em si, mas de esclarecer, contestar, criar ou fornecer insights sobre um tema (STAKE, 1998). No caso desse estudo, o tema refere-se à gênero e sexualidade nas aulas de Educação Física.

A observação de campo evidenciou a relevância deste tema, já que em diversos momentos, detectaram-se indicativos de mobilização maior dos meninos perante as meninas, o que nos levou a analisar a influência do marcador de gênero na relação dos alunos com os saberes das lutas. Vale ressaltar que tal contexto está em acordo com o paradigma de pesquisa qualitativa, cuja metodologia admite um pequeno grau de 
estruturação prévia, e flexibilidade nos procedimentos em função do desenrolar do trabalho (ALVES-MAZZOTTI, 1999).

Na ocasião, como delimitação da problemática de pesquisa, foi selecionado uma turma de alunos que não havia aprendido o conteúdo lutas nas aulas de EF, de modo que tal situação permitiria também analisar suas expectativas. A rede pública estadual de São Paulo, no munícipio de Bauru, foi tomada como locus da investigação, já que o eixo de conteúdos "lutas" está presente no Currículo de Educação Física do Estado de São Paulo (CEF-SP) em cinco ocasiões. Como no $7^{\circ}$ ano do Ensino Fundamental se dá o primeiro contato dos alunos com o conteúdo lutas (judô), este foi o ano escolar elegido. Outro critério estabelecido levou em consideração a história de vida do professor(a), que não contemplou participação como praticante/atleta de qualquer modalidade de luta, o que garantiu uma situação compatível com o perfil da maioria dos professores de Educação Física, em termos de conhecimento do conteúdo. A escola selecionada localiza-se na periferia de Bauru, e contava com três professoras de EF; no entanto, apenas uma ministrava aulas nas turmas de $7^{\circ}$ ano. A turma investigada possuía 31 alunos, composta por 16 meninas e 15 meninos

As etapas do estudo maior consistiram em: (i) entrevista inicial com a professora do $7^{\circ}$ ano do Ensino Fundamental; (ii) familiarização com a turma observada (observação de nove aulas do conteúdo voleibol); (iii) entrevista inicial semiestruturada com 12 discentes (sendo apenas quatro alunas) ${ }^{6}, 7$, selecionados aleatoriamente por sorteio, do $7^{\circ}$ ano do Ensino Fundamental registrado em gravador de voz (histórico de prática de lutas, expectativas e opinião em relação ao conteúdo lutas); (iv) observação das aulas com registro em diário de campo (quatro aulas de judô); (v) entrevista final semiestruturada com 17 discentes $^{8}$ (sete meninas), sendo os mesmos doze alunos selecionados inicialmente, mais cinco escolhidos intencionalmente a partir de indícios provenientes das observações de campo (três meninas que se autoexcluíram das aulas; e dois meninos que demonstraram excessiva mobilização), que os qualificaram como bons interlocutores (opinião em relação às aulas do conteúdo lutas; o que aprenderam nas aulas; interesse em relação ao conteúdo lutas); e (vi) entrevista final com a professora, sobre o detalhamento de situações ocorridas em aula. Para a pesquisa em questão, nos valemos das entrevistas semiestruturas com os 17 alunos (10 meninos e 7 meninas) do $7^{\circ}$ ano do Ensino Fundamental ao final das intervenções e as observações das aulas do conteúdo Judô.

Os dados serão apresentados de modo descritivo e interpretados a partir da "triangulação" das diferentes fontes (conhecimento do conteúdo/tema, planejamento das aulas, observação das aulas e entrevistas) e pelo diálogo/confronto com as questões teóricas postas pela literatura.

6 A amostra de 12 alunos entrevistados respeitou a percepção do pesquisador, que, imerso no campo de pesquisa, em um momento inicial, considerou tal quantidade de informantes suficiente e possível de serem entrevistados no prazo disponível.

7 Como a discussão sobre gênero e sexualidade não foi eleita a priori como questão elencada na atual investigação, o fator amostral do gênero (limitação do estudo) não foi considerado como critério de representatividade.

8 Quando foi percebida menor mobilização das meninas nas aulas de judô, foram selecionadas intencionalmente mais três alunas (Julia, Elisabete e Liliana) para a entrevista final. 
A observação de campo e as entrevistas realizadas foram subsidiadas pela teoria da relação com o saber desenvolvida por Bernard Charlot; sendo assim, demos foco nas relações de sentido e mobilização dos discentes, bem como suas relações sociais, epistêmicas e identitárias com conteúdo lutas. Especificamente, durante a etapa de observação das aulas, as relações de gênero mostraram-se relevante, o que demandou uma abordagem particular nas entrevistas semi-estruturadas finais. Isto é, existia menor mobilização das meninas? Se sim, quais eram os motivos? Neste sentido, foram elaboradas duas questões específicas para problematizar e desvelar o tema, as quais serão expostas no desdobramento do texto. Diante dos depoimentos dos discentes, diversas narrativas evidenciavam pontos de vistas em comum, o que levou à criação de categorias de análise.

Os alunos estão identificados por pseudônimos escolhidos pelo pesquisador. Aqueles que declararam ter vivenciado lutas fora da escola receberam pseudônimos de personagens do universo das lutas, tais como super-heróis, artistas marciais e deuses da mitologia greco-romana. Já os alunos sem vivência prévia em lutas foram identificados com nomes habituais.

\section{Elementos que indicaram menor participação das meninas nas aulas de lutas: a "periferia do dojo"}

Embora convivamos com maior inserção de mulheres nas lutas, a atual observação evidenciou menor participação e mobilização das meninas em comparação aos meninos. É nesse sentido que se empresta o conceito de "periferia da quadra" de Oliveira e Daolio (2014), para subsidiar a análise de alguns momentos desvelados na observação de campo. Com inspiração em referenciais da antropologia urbana, a periferia da quadra é o entendimento de que as aulas de Educação Física possuem múltiplas relações de espaço-tempo que são ocupadas e usufruídas por diferentes alunos, de modo a reconhecer que o envolvimento discente se dá de modo plural. Para os autores, nas aulas de Educação Física, mesmo aqueles alunos que se colocam numa relação de distanciamento com os conteúdos centrais propostos pelo professor, também apresentam algum tipo de participação.

É nas margens da quadra, afastados da proposta de aula do professor, que alguns alunos ocupam um espaço-tempo que inspirou o termo "periferia da quadra". Embora tratado como um todo periférico, a periferia da quadra possui subdivisões internas: o "pedacinho (im)praticante" (por exemplo: sentar na arquibancada, não se expor) e; "pedacinho ativo" (brincar com colegas nas margens da quadra, jogar "bobinho" no canto enquanto espera ser chamado, dentre outras situações) (OLIVEIRA; DAOLIO, 2014).

Nesse sentido, o envolvimento dos alunos com as lutas produz uma periferia particular em comparação à quadra de Oliveira e Daolio (2014). Analogicamente, denominamos de "periferia do dojo", o tempo e espaço paralelo à atividade principal de luta ministrada pelo professor, é onde se produz modos particulares de mobilização e engajamento, marcados, sobretudo, pelas relações de gênero. Destacamos, a seguir, alguns contextos das aulas que indicaram condutas que não foram capazes de mobilizar as meninas. 
O primeiro contexto diz respeito à organização espacial. Ele pode ser verificado na primeira e na terceira aula, respectivamente, em uma atividade expositiva com recursos audiovisuais, e outra de jogos de lutas. Em ambos momentos, meninas e meninos posicionaram-se separadamente. Na primeira aula, todas as meninas ocuparam as últimas cadeiras; já na terceira aula, antes dos jogos de lutas, os meninos permaneceram em diferentes espaços da sala e as meninas continuaram agrupadas. Vale ressaltar que, quatro meninas não participaram da terceira aula, mas estiveram presentes nas aulas de voleibol, conteúdo antecedente ao judô, o que demonstra uma especificidade da ocupação de espaços-tempo das aulas. Além disso, notou-se que as meninas quando comparadas aos meninos, com exceção de Atena, expressavam tédio e participavam menos das atividades.

As meninas colocaram-se em um plano de fundo nestas situações, constituindo-se como em um "pedacinho (im)praticante" na periferia (OLIVEIRA; DAOLIO, 2014). A exclusividade feminina nas margens da aula, de modo alheio à Educação Física, não é algo novo. Todavia, chama atenção que esta forma de ocupação se deu em uma atividade expositiva, que não demandava exposição "física" que pudesse constrangê-las pela dificuldade em realizar movimentos. Consideramos isso particular porque, como já constataram Uchoga e Altmann (2016), a autoexclusão das meninas, em geral, está relacionada ao medo de "se arriscar" nas aulas, isto é, de se expor diante de uma tarefa desconhecida ou pôr em evidência uma suposta inabilidade, em comparação aos meninos.

Em segundo momento, a periferia do "dojo" também se constituiu como um tempo e espaço para a prática de movimentos de lutas como alternativa à atividade principal, que demandava um longo tempo de espera para realização de algum movimento ou golpe sob supervisão da professora. Diante disso, nas aulas 2 e 3, os alunos Bruce Lee e Ranger Verde criaram um novo dojo com as placas de EVA ignoradas pela professora. Era um espaço em que os alunos praticavam judô, compartilhavam conhecimentos de outras lutas e aprimoravam suas habilidades, enquanto esperavam ser chamados pela professora. No entanto, mostrava-se pouco democrático e inclusivo, pois era frequentado exclusivamente pelos meninos, e por Atena, a única representante das meninas.

Esta periferia do dojo, constituída como um "pedacinho ativo" (OLIVEIRA; DAOLIO, 2014), produzia formas distintas de arriscar-se às habilidades e aprendizagens apresentadas nas aulas (UCHOGA; ALTMANN, 2016). A periferia, neste caso, constituiu uma área de não-diretividade pedagógica, disponível para aperfeiçoamento das habilidades, mas que também reproduziu os valores sociais relacionados às lutas, como é o caso da predominância masculina.

Para melhor interpretar esses indícios supracitados, realizamos duas perguntas na entrevista final: "na aula 1, todas as meninas sentaram no fundo e os meninos sentaram na frente, por que você acha que aconteceu isso?" e "você acha que os meninos ou as meninas se interessaram mais pelas aulas de luta? Por quê?". Em referência à primeira questão, a grande maioria dos discentes acreditou que as meninas recusaram os conteúdos das lutas, de modo que adotaram uma posição mais passiva nas aulas, como é o caso de sentar-se nas carteiras mais distantes. Quanto ao segundo questionamento, todos os entrevistados responderam que os meninos tiveram participação mais intensa em comparação com as 
meninas em todas as aulas de judô. As justificativas para tal afirmação foram separadas em três categorias que demonstram elementos desfavoráveis à mobilização feminina: (i) a masculinização e o machismo na luta; (ii) o medo de machucar-se; (iii) vergonha de se expor.

\section{Masculinização e machismo como elementos desfavoráveis à mobilização feminina}

Nesta categoria serão abordadas, as justificativas discentes de menor participação de meninas nas aulas. Nesse sentido, a falas relacionam a luta como uma expressão corporal masculina e, por consequência, não adequada aos interesses femininos.

"As meninas não gosta, porque as meninas não é dessas meninas de gostar desse negócio de briga" (Paulo).

"As meninas não se interessam por lutas [...]. Talvez pelo fato [do menino] ser brigão [...]. Não sei, deve ser machismo" (Stalone).

"Os meninos só gosta de lutar e essas coisas de futebol" (Ana).

“Ah! Eles gostam mais, né? Porque coisa de briga, moleque é muito mais interessado" (Carl Johnson).

"Pelo fato de ser uma luta também, que eles gostam bastante. Eles gostam bastante de brincar, aprender mais golpes, acho que eles se interessaram mais nisso" (Elisabete).

“Ah, acho que os meninos têm mais interesse pelo Judô do que as meninas [...] Porque acho que a luta é mais masculina assim [...]. Ah, porque eu acho que o masculino já nasce assim com negócio de lutar, de briga, essas coisas. Então, é o sexo mais forte, então acho que é masculino mesmo (Liliana).

Tais discursos compactuam com Wacquant (2002), para quem, os jovens praticantes de boxe entendem a modalidade como tempo e espaço para expor e dar sentido à própria masculinidade, de tal modo que a participação de mulheres é pouco tolerada. Wacquant (2002, p. 76) apresenta o ethos masculino do boxe relacionando "a coragem física, a honra individual e de desempenho corporal". Estes atributos são relacionados à virilidade, à exibição de um capital corporal manifestado pela força e pela violência, mesmo submetida a disciplina dos códigos das lutas e de seus espaços de treinamento. Nestes códigos, não há a presença do feminino de forma a ser dotada de um significado próprio. Ao contrário, o feminino apareceria por fora das lutas, mediante a sexualização de seus corpos.

Nas últimas décadas, no entanto, as mulheres têm adentrado aos ringues como lutadoras, performatizando estes atributos também. No entanto, fazem questão de ratificar suas "feminilidades normalizadas", aparecendo maquiadas, femininas, delicadas (FERNANDES et al., 2015, p. 375). Este hibridismo demonstra as plurais feminilidades 
postas em circulação quando as mulheres lutam, afirmando um espaço possível para as mesmas, a despeito dos efeitos dos discursos masculinizantes relacionados à prática.

Em segundo lugar, o discurso da masculinização aparece travestido das habilidades exigidas pelas lutas, as quais as mulheres não teriam aptidão ou interesse:

“Elas gostam de jogo mais fácil, jogo mais calmo [...]. Porque elas gostam desse jogo mais leve, mais feminino assim" (Atena).

"Acho que eles se sentiram mais motivados porque a luta envolve muito movimento assim. Agilidade. Por isso [os meninos] queriam mais participar" (Julia).

“Os meninos gostam mais de lutar, as meninas não são muito chegada[...] as meninas brincam mais de boneca, essas coisas" (Ana).

Para Wacquant (2002), historicamente, a luta é considerada uma modalidade masculina, provedora de habilidades como suportar a dor, desenvolver a força física e espiritual. Quando afirmam que as mulheres não são dotadas das habilidades necessárias às lutas, produz-se uma naturalização de seus corpos, informando, a partir de uma biologia não desinteressada, a sua fragilidade e incapacidade. Outra justificativa que restringe a participação feminina considera o corpo como um instrumento passivo sob qual a cultura se imporia (BUTLER, 2014). Tais discursos, em maior ou menor medida, estiveram presentes ao longo do século XX e justificaram a proibição de modalidades esportivas às mulheres (GOELLNER, 2007).

Por este fator tradicional de associar as lutas com a presença masculina de resistência a dor e a virilidade, a menor mobilização das meninas é gravemente justificada por discursos discriminatórios que de certa forma reduzem a complexidade do tema:

"O resto ficou aqui sentada só observando [...] com certeza era pra conversar, escutar música e não prestar atenção [...] você acha que as meninas vão trazer blusa (larga) de casa para colocar e sujar aqui no chão? Ah tá. Nem minha prima vai fazer isso" (Hulk).

“Acho que elas não gosta, né? De assistir essas coisas [...] Porque daí não é pra elas [...] Ah, elas não gostam de quebrar a unha" (Ranger Verde).

“As meninas não gostam de lutas eu acho. Gosta de se maquiar a maioria, e para ficar zoando lá atrás" (Lucas).

Os discursos dos alunos indicam um não lugar das meninas nas lutas, afinal, justificam o distanciamento não apenas pela violência causada ou pela fragilidade corporal biológica, mas pelo desinteresse cultural que as meninas teriam. Nesse sentido, não fazem da biologia o destino que as afasta das lutas, mas da cultura, reafirmando uma relação mimética entre sexo e gênero (BUTLER, 2014). 
Estas justificativas, que tratam o corpo como destinatário, ora da biologia, ora da cultura, possuem algo em comum, que é o caráter de passividade. Eles também possibilitam a ascensão de preconceitos às mulheres que ousam transgredir e subverter esta ordem. No enquadramento normativo que iguala sexo, gênero e orientação sexual (BUTLER, 2014), tais mulheres não se encaixam e, por conseguinte, tem sua sexualidade questionada, como é possível vislumbrar a fala a seguir:

"Ah, tem alguns meninos que acham esquisito as meninas lutarem, que acham feio [...] Tem alguns alunos que julgam as meninas: - nossa, você tá lutando [...] Uma menina [Atena] me chamou, daí quase eu perco dela. E os meninos falavam: - nossa, parece homem lutando, Maria-homem" (Bruce Lee).

Tal discurso esboça uma situação ocorrida na periferia do dojo, no pedacinho ativo, onde os alunos, não-diretivamente ${ }^{9}$, compartilhavam golpes e lutavam no fundo da sala. Atena foi a única menina que participou deste espaço-tempo da periferia do dojo. Nesse pano de fundo, quando parte dos meninos chamam Atena de "Maria-homem", implicitamente diziam que a luta - neste caso, o judô - é masculina, devendo ser praticada apenas por meninos. As críticas à luta de Atena com Bruce Lee representaram uma resistência em aceitá-la como lutadora e, mais do que isso, significava romper com o domínio masculino daquele espaço. Ferretti (2011) afirma que, nas lutas, as mulheres enfrentam duas hierarquias: uma entre homens e mulheres; e outra entre as próprias mulheres. $\mathrm{O}$ autor entende que, mesmo quando uma mulher é mais graduada que um homem, este ainda se acha superior. Como exemplo, relata que, quando homens menos graduados perdiam o combate para mulheres, não se conformavam com o resultado.

Todavia, Bruce Lee mencionou seu interesse na participação das meninas, demonstrando que não se sentia ameaçado com a presença feminina. Sendo um praticante de lutas, o aluno pode ter compreendido que a entrada da mulher em modalidades como as de lutas não feminiliza o ambiente, pelo contrário, existe uma aderência da mulher aos valores considerados masculinos (FERRETTI, 2011; FERNANDES et al., 2015).

Helena Altmann (1998) estudou um contexto em que meninos não aceitavam a participação das meninas, sobretudo, por considerá-las inabilidosas. O caso da periferia do dojo pode ser interpretado à mesma maneira, na medida em que a participação de Atena entre os meninos deveu-se à sua habilidade para lutar. Evidentemente, a questão da habilidade está relacionada a uma construção cultural dos corpos distinta, via de regra, entre meninas e meninos, sendo que a estes últimos costumam ser oportunizadas mais experiências e vivências de práticas corporais, se comparados às primeiras (GOELLNER, 2010).

Elisabete e Liliana associam a mobilização dos meninos pelas lutas com as brincadeiras de "lutinha" ou de algumas brigas realizadas no cotidiano da escola, como se essas atividades promovessem familiarização com o conteúdo: 


\begin{abstract}
"Ah, pelos fatos deles terem essas brincadeirinhas, vou dizer estúpidas, um com outro assim, eles já levaram mais na brincadeira, começaram dá soco assim, e eles não levaram a sério". (Elisabete).
\end{abstract}

“Porque os meninos são mais briguentos, essas coisas. Então acho que eles se interessaram mais". (Liliana).

De fato, Altmann (1998) já relatava que meninos jogavam, no recreio e nos intervalos, jogos que envolviam socos, como "pimentinha", em que o aluno que dissesse alguma palavra que iniciasse com " $\mathrm{P}$ " seria alvo de golpes até que proclamasse a expressão "Pimentinha". Ainda conforme a autora, "dar o soco" na brincadeira significava posicionar sua masculinidade acima do outro, mostrando a todos força e virilidade. Todavia, o aluno que não se envolvia na atividade era chamado de homossexual. Ainda no mesmo estudo, foram observadas vinte ocorrências de briga entre os meninos, contra apenas uma de meninas.

Desse modo, os jogos de lutinha/briga durante os intervalos das aulas são ferramentas que tornam o conteúdo lutas mais familiar aos meninos por duas vias: porque brincam de jogos que envolvem força e agressividade, e porque brigam mais. Esta relação reforça à valorização da violência como um dos aspectos do praticante das lutas, conforme já descrito por Wacquant (2002) como parte do ethos do lutador de boxe do gym dos guetos de Chicago.

\title{
O medo de se machucar como elemento desfavorável à mobilização feminina
}

A segunda vertente trata do medo de se machucar das meninas como barreira para a participação intensa das aulas de Educação Física:

“Porque as meninas tinha mais medo de se machucar, esse tipo de coisa. [...] Porque a maioria das meninas ficaram mais para trás. Na hora também não queria fazer. Tinham medo de se machucar, até falaram." (Chuck Norris).

"Elas não quiseram muito para não se machucar". (Lucas)

Sobre a hipótese do medo de se machucar, dois momentos marcaram a não-participação de parte das meninas: a vivência do golpe o-soto-gari ${ }^{10}$ (orientado pela professora) e a atividade livre no tatame montado no fundo da sala (pertencente à periferia do dojo). Na atividade do o-soto-gari, sempre um dos alunos da dupla executava o golpe, enquanto o outro não oferecia resistência para cair no solo, ou seja, "se virava" para jogar-se no chão sem machucar. De certo, nenhum aluno se machucou na atividade, pois a aplicação do golpe deveria suceder devagar e sem movimentos bruscos, no intuito de

10 Trata-se de um golpe de desequilíbrio do judô. 
proteger a integridade física do outro. Já no fundo da sala, os frequentadores da periferia do dojo faziam movimentos de judô e de outras lutas como bem entendiam, sem orientação da professora. Muitos gestos eram bruscos com o real objetivo de derrubar o colega, o que de fato tornou improvável a participação das meninas com medo de se machucar.

Julia e Elisabete pertenceram ao grupo de alunas que recusaram a prática do o-soto-gari. Segundo as falas das alunas, tal atitude é decorrente de uma insegurança para iniciar a prática do judô, mesmo nos garantindo que haviam vontade de participar da atividade, mas o receio de se machucar era maior:

\footnotetext{
“Porque, tipo, não é nem problema de força de vontade, é mais por medo. De ir e acontecer alguma coisa. Eu fui com medo assim [...] medo de acontecer alguma coisa, de machucar." (Julia)
}

\begin{abstract}
"Pelo medo de machucar [...] eu fiquei meio indecisa que ainda eu fiquei perto da professora, daí eu falei assim: - Ah, eu vou [praticar o golpe o-soto-gari]! Aí depois, eu olhei a pessoa que eu ia, e falei: - Ah, não vou mais. Daí fiquei insegura, de ir com a pessoa." (Elisabete)
\end{abstract}

O empreendimento de se arriscar e de tentar movimentos desconhecidos nas aulas de Educação Física é identificado como distinto entre meninas e meninos em função de alguns fatores (UCHOGA; ALTMANN, 2016). Entre as razões que promovem essa distinção no engajamento estão o desconforto com implementos novos e movimentos considerados difíceis. De acordo Uchoga e Altmann (2016), estas razões são corroboradas muitas vezes por professores de educação física, diretores da escola e pais, justificadas pelo medo de "se machucar", que afeta, via de regra, somente o engajamento das meninas com essas atividades.

Todavia, quando esses sujeitos se encontram em outras relações identitárias e sociais, o "arriscar-se" pode se tornar seguro. Essa possibilidade foi aventada na fala de Elisabete, segundo a qual ela afirmou que não se sentiu segura para praticar o o-soto-gari, embora estivesse com vontade. No entanto, esta vontade foi extrapolada fora da escola, quando a aluna relatou ter praticado o golpe com seu pai, dentro de casa:

\footnotetext{
“Meu pai já praticava alguma luta já, aí eu falei para ele que aprendi alguns golpes, aí eu brinquei com ele ainda [...]. A gente só brincou mesmo, e eu mostrei o que aprendi para ele, mesmo sem ter participado da aula de Educação Física. [...] Foi um pouco difícil de derrubar, mas consegui [...] Daí ele falou: - não, coloca mão direita e não sei o quê. Porque tinha que segurar assim na blusa da pessoa, e a pessoa segurar na sua e tentar [...] [Se houvesse próxima aula] poderia brincar com mais coragem. [...] Eu tentei e consegui! Aí perdi o medo assim de: - Ah, a pessoa vai me machucar." (Elisabete).
}

Este episódio demonstrou, nos termos de Charlot (2000), como a "relação identitária", de afeto e confiança, proporcionou segurança à Elisabete para que superasse seu medo de se machucar. Daí faz-se essencial o papel docente em lidar de maneira mais particular 
com essas alunas, abrindo diálogo e permitindo-lhes construir sentidos na relação consigo mesmo, com outro e com o mundo.

Ora, mas isso significa que meninos não têm medo de se machucar no solo? Pelo contrário, muitos são os meninos que demonstraram este medo de se machucar. Constatado na entrevista inicial, Paulo, Anderson e Lucas não desejaram aprender o conteúdo lutas, para não se machucarem. Entretanto, mesmo com uma recusa inicial, estes alunos participaram intensamente por perceberem que o judô não possuía socos e chutes como imaginavam, mas movimentos de agarre, retenção, quedas e imobilização, os quais julgaram ser menos violentos. Todavia, conforme Anderson, outro argumento favoreceu a participação, a integração ou não-exclusão do ambiente masculino: "os outros tavam tudo falando que iam praticar, daí eu não queria ficar sozinho [...] porque quase todos moleques fez e eu não ia ficar com as meninas.". Integrar com os meninos significou duas coisas: não integrar-se ao ambiente feminino (das alunas que não participaram das aulas); e exercitar a virilidade, o controle da dor, a força e a agressividade, tão presentes no universo masculino.

No âmbito do controle da dor e no exercício da virilidade, afirma Hulk:

“Ó, eu aprendi também que (judô) não é difícil, é muito fácil. Mas tem que ser preparado pra dor, como doeu quando o Chuck Norris me derrubou [...]. Eu também aprendi que é melhor ganhar do que perder [...] É muito doloroso perder, principalmente quando é o Chuck Norris que te derruba no chão."

Conforme elucida Wacquant (2002), a tolerância à dor torna-se uma característica da cultura masculina dos pugilistas. Nesse sentido, exercer a virilidade é suportar a dor e não demonstrá-la, estar preparado para as adversidades e o choro, não é dizer que não se tem medo dela, é ter prazer em sofrê-la. No entanto, estas diferentes formas de lidar com o medo e com a dor, entre meninos, demonstra que as masculinidades também são plurais, de modo que a não linearidade entre sexo-gênero-desejo, bem com a performatividade do gênero, se expressam nas formas distintas pelas quais meninos se envolvem nas lutas.

\section{A vergonha como elemento desfavorável à mobilização feminina}

A vergonha das meninas de se exporem nas aulas de lutas também é um dos fatores para a não-participação das aulas de Judô. Elektra esboçou bem este sentimento: "acho que é vergonha de fazer alguma coisa errado e os meninos começar a zoar [...] na luta os meninos já está craques. As meninas não sabem quase nada". Novamente, a questão da suposta superioridade de habilidade dos meninos é entendida como um fator de constrangimento, de posição impositiva, dominadora e, principalmente, avaliativa e comparativa perante as meninas.

Alguns alunos acreditam que exista um desconforto ao pôr-se a vista para outros colegas, especialmente das meninas para os meninos: 


\begin{abstract}
“na luta você já tá num espaço pequeno, todo mundo te olhando, dá mais vergonha ainda [...] [Durante a atividade do o-soto-gari] Primeiro iam lutar os meninos. Aí na hora que eles fossem sentar e fossem as meninas, os meninos não vão ter o que fazer, vão ficar olhando as meninas derrubar uma com a outra" (Elektra).

"Acho que elas sentiram vergonha" (Morfeu).

“Porque as meninas têm um pouco de vergonha, bastante vergonha [...] São tímidas, ficam tímidas na aula de lutas [...] Assim, vergonha dos meninos verem e ficarem dando risadas. Achar assim, menina lutando" (Bruce Lee).
\end{abstract}

Cabe refletir, todavia, do que se tratava essa vergonha? Insegurança de quais fatores? Segundo a fala dos alunos, o receio da exposição deveu-se à zombaria dos meninos para com as inabilidades das meninas. Dessa forma, o medo de errar, de mostrar incompetência na realização dos movimentos desencadeia a (auto) exclusão da atividade. Percebemos a vergonha e o medo como atravessadas pelo marcador de gênero. Conforme Uchoga e Altmann (2016), nas aulas de Educação Física, sobretudo quando não há intervenção pedagógica, o fato de os meninos se arriscarem mais a tentar movimentos diferentes do que as meninas não significa que eles não errem ou que não tenham momentos de exposição de inabilidade. Ao contrário, suas tentativas sem êxito não fizeram com que se machucassem, mas que ampliassem o conhecimento destes movimentos ao fim das aulas.

Vale ressaltar que a dinâmica da terceira aula, do ensino do golpe o-soto-gari, valeu-se de alunos divididos em duplas, por sexos e organizado sequencialmente no modelo de dois por vez no centro da sala. Esse cenário favoreceu um grande número de espectadores que esperavam pela vez de praticar o golpe, e isso potencializou a vigília entre os alunos. A vigília propicia a vergonha não pelo simples olhar que é fruto dela, mas pelo olhar "disciplinador", que encerra lugares específicos aos corpos. De acordo com Foucault (2013), a disciplina age como modo de exercer poder que estrutura o campo de ações possíveis dos outros. Neste caso, o campo de ações da menina é diferente do menino e o olhar disciplinador do outro cria uma sensação de vigilância, internalizada, que faz com elas não se arrisquem à subversão do papel que Ihes foi destinado. De acordo com Altmann (1998, p.39), "o funcionamento automático do poder é um estado consciente e permanente de visibilidade", portanto, "o aluno ou a aluna pode não estar sendo vigiado, mas tem a certeza de poder estar, o que assegura a automatização e a desindividualização do poder".

Por um lado a estratégia "dois alunos por vez no centro da sala" favoreceu o trabalho docente, pois permitiu maior controle da situação, bem como maior atenção para os alunos. Todavia, por outro lado, poderia ser mais produtivo o desenvolvimento das atividades com diversas duplas simultâneas, mesmo que isso significasse maior complexidade e esforço para o professor. Tal estratégia minimizaria o tempo de espera dos alunos e, consequentemente, a sensação de vergonha ocasionada pela observação dos colegas.

Este sentimento de vigilância faz com que o sujeito adote certas condutas e hábitos para evitar um constrangimento maior dos observadores, como é o caso da autoexclusão de Elektra nas aulas de Educação Física. Nesse sentido, o olhar e a zombaria promovidos 
pelos meninos funcionariam como a sanção disciplinar àquelas que não colocaram seus corpos dentro das normas da inteligibilidade cultural do gênero. Dessa forma, para a aluna, não foi fácil uma tomada de atitude para participar das aulas de judô, já que convivia com imaginário de ser zombada por suas inabilidades:

"Eu fiquei meio assim, vou passar vergonha, ela vai me derrubar, todo mundo vai filmar e todo mundo vai zoar da minha cara. Mas aí depois eu falei: - Professora, me ensina o golpe de novo. Daí ela fez eu aplicar o golpe na Atena pra depois a Atena aplicar o golpe em mim. A princípio eu fiquei com vergonha, mas depois eu me soltei mais. Depois eu já queria treinar com todo mundo". (Elektra).

Altmann (1998) ainda afirma que a inibição, a vergonha, a timidez, tornam-se mais intensas quando esta vigilância é exercida entre gêneros diferentes. Na presença de um observador do outro gênero, o sujeito faz atividades adequadas a seu estereótipo sexual. A pesquisadora constatou que quando os meninos estavam ausentes, as meninas agiam de maneira distinta em comparação ao modelo de feminilidade. Nesse sentido, Elektra assumiu que ficou mais à vontade quando os meninos interagiam na "periferia do dojo", deixando o palco principal para as meninas. Isso significa que a sensação de vigilância e de controle do poder por parte dos meninos desapareceu, e assim também se dissipou a artificialidade de comportamento: "depois que eu achei legal, eu me soltei mais [só] quando os meninos foram lutar no canto deles. Deixou a gente tentar sozinha" (Elektra).

Vale destacar, a mediação docente de dar devida atenção a uma aluna que estabelecia sentido com o conteúdo judô, mas pelo excesso de vergonha, não pôde expressar sua mobilização prontamente. Isso reforça a ideia que a aprendizagem depende de mediação em uma relação consigo mesmo, com os outros e com o mundo (CHARLOT, 2000).

Ademais, em relação a mediação do outro para a aprendizagem, a aluna Atena também desempenhou papel de grande valia na dinâmica das aulas, pois "recrutou" três meninas que ainda não tinham participado da aprendizagem do golpe: Elektra, Kelly e Dirce. Atena, na busca de colegas para a prática do o-soto-gari, não encontrou alternativa além de persuadir e convencer outras meninas. Nesse sentido, na medida em que se cria um envolvimento social de pelo menos uma menina, isto pode ser motivador para que outras venham a mobilizar (DEEM; GILROY, 1998). Este comportamento também contribuiu para tensionar as fronteiras da inteligibilidade de gênero, oportunizando às meninas a possibilidade de se arriscar diante das lutas, mesmo elas interpretando este conteúdo como masculino.

A aluna Elektra ainda sugeriu a separação entre meninas e meninos nas aulas de lutas, assim como já foi feito pela professora, mas com um adicional, que meninas e meninos participem simultaneamente em espaços delimitados e, portanto, eliminando o fator de vigília entre sexos diferentes:

“Eu acho que a professora podia colocar meio que uma faixa aqui no meio e dividir menino de menina. Porque as meninas iriam perceber que os meninos estão prestando atenção só do lado deles e iam se soltar mais" (Elektra). 
A separação das aulas de educação física é um tema recorrente nas discussões sobre a organização pedagógica da disciplina. Alguns autores defendem, tal como Elektra, que as aulas separadas seriam pedagogicamente interessantes para que os alunos vivenciassem situações de aprendizado em grupos mais homogêneos, com níveis de habilidades parecidos (DORNELLES; FRAGA, 2009). De acordo com os autores, por trás deste argumento, reside a perspectiva do rendimento como organizador dos princípios da aula. Além disso, se o critério seria a homogeneidade física, por que não separar por idade ou por nível de habilidade em vez de sexo, indagam os autores (DORNELLES; FRAGA, 2009). Tal questionamento visa evidenciar que o discurso biológico da naturalização dos corpos de meninas e meninos pelo viés do sexo, tornando a biologia "o destino" dos corpos e das habilidades dessas crianças e jovens (BUTLER, 2014).

Se por um lado, aulas separadas podem acentuar a generificação das aulas, por outro, as aulas mistas por si só não garantem uma problematização de gênero nas aulas de Educação Física, tampouco oportunidades iguais de aprendizagem, como demonstra a fala de Elektra. Dornelles e Fraga (2009) argumentam como apenas fazem com que meninas e meninos permaneçam juntos no mesmo espaço e tempo das aulas de Educação Física não faz com que as atividades sejam menos generificadas, sendo necessário fugir dessas respostas simplistas e observar e refletir sobre o cotidiano escolar a fim de desnaturalizar práticas correntes nas aulas de educação física.

\section{CONCLUSÕES}

O ensino de lutas nas aulas de Educação Física é atravessando por tensões relacionadas às questões de gênero e sexualidade, o que, por sua vez, pode favorecer a sua exclusão do conteúdo próprio da disciplina. A atual investigação apontou, a partir da observação das aulas e discursos discentes, elementos que desfavoreceram a mobilização de alunas nas aulas de lutas. Diante do exposto na investigação, as lutas mostram-se um conteúdo imprescindível, especialmente ao oferecer uma oportunidade de quebra de estereótipos e preconceitos, como foi notado nos discursos discriminatórios e a frequente associação da luta com o gênero masculino.

Nesse sentido, esta investigação forneceu algumas pistas para melhorar a construção de conhecimento pedagógico das lutas em relação às questões de gênero, e assim favorecer a intervenção do professor quanto a participação feminina: (i) faz-se essencial contextualizar e tematizar questões de gênero com intuito de romper estereótipos, por exemplo: quem frequenta os espaços das lutas? As lutas podem ser praticadas por homens e mulheres? Por que há maior presença de homens praticando lutas? (ii) sugere-se as trocas constantes das duplas, inclusive entre meninas e meninos, o que pode auxiliar as discussões de gênero; (ii) garantir que as aulas de lutas sejam diretivas, já que o "deixar-fazer" nas lutas (como foi o caso da periferia do dojo) reproduziu os estereótipos das lutas, sobretudo reforçando o machismo e a menor participação feminina. (iii) propõe-se maior exploração dos jogos de lutas bem como o ensino de rolamentos no judô, com o intuito de minimizar o medo 
de se machucar das meninas; (iv) a estratégia de "dois alunos por vez ao centro da sala" favoreceu a sensação de vergonha em expor as habilidades, dessa forma, a percepção de vigilância relatada pelas meninas pode ser minimizada na formação de duplas simultâneas; (v) é importante uma postura dialógica e de curiosidade em situações de não-participação feminina, particularmente, identificar as relações de sentido e de mobilização com as lutas.

Vale ressaltar que as relações identitárias e sociais podem transformar a autoexclusão em participação, remodelando seus sentidos; como foi o caso da mediação persuasiva de Atenas com três alunas, da intervenção pedagógica de qualidade da professora com Elektra, da prática do golpe o-soto-gari de Elisabete com o próprio pai. Por fim, entendemos que ressaltar as dificuldades do tema gênero e lutas não significa descartá-las do processo pedagógico, mas de incentivar a criação de experiências que subvertam e transgridam tais barreiras.

\section{REFERÊNCIAS}

ALTMANN, Helena. Rompendo fronteiras de gênero: Marias (e) homens na educação física. 1998. 111 f. Dissertação (Mestrado) - Curso de Mestrado em Educação, Faculdade de Educação, Universidade Federal de Minas Gerais, Belo Horizonte, 1998.

ALVES-MAZZOTTI, Alda Judith. O método nas ciências sociais. In: ALVES-MAZZOTTI, Alda Judith; GEWANDSZNAJDER, Fernando. O método nas ciências naturais e sociais: pesquisa quantitativa e qualitativa. 2. ed. São Paulo: Pioneira, 1999. Parte II. p. 107-188.

. Usos e abusos dos estudos de caso. Cadernos de Pesquisa, [s.I.], v. 36, n. 129, p.637-651, dez. 2006. FapUNIFESP (SciELO). http://dx.doi.org/10.1590/s010015742006000300007.

BETTI, Mauro; USHINOHAMA, Tatiana Zuardi. Os saberes da Educação Física nas perspectivas dos alunos: panorama da literatura e uma proposta de investigação a partir da 'teoria da relação com o saber'. Revista Pulsar, Jundiaí, v. 6, n. 4, p.1-18, jul. 2014. Disponível em: < http://pulsar.esef.br/index.php?option =com_content\&view = article $\& \mathrm{id}=1197$ :volume6numero042014\&catid = 70:pesquisa $>$. Acesso em: 14 jul. 2018.

BUTLER, Judith. Problemas de gênero: feminismo e subversão da identidade. 7. ed. Rio de Janeiro: Civilização Brasileira, 2014.

CHAN-VIANNA, Alexandre Jackson; MOURA, Diego Luz. MOURÃO, Ludmila. Educação Física, gênero e escola: uma análise da produção acadêmica. Movimento, Porto Alegre, v. 16, n. 2, p.149-164, jun. 2010. Trimestral. Disponível em: < http://seer.ufrgs.br/index. php/Movimento/article/view/9492/8925>. Acesso em: 14 maio 2018.

CHARLOT, Bernard. Da relação com o saber: elementos para uma teoria. Porto Alegre: Artmed, 2000.

. Os jovens e o saber: perspectivas mundiais. Porto Alegre: Artmed, 2001.

CORREIA, Walter Roberto; FRANCHINI, Emerson. Produção acadêmica em lutas, artes marciais e esportes de combate. Motriz. Revista de Educação Física. Unesp, [s.l.], v. 16, n. 1, p.1-9, 19 nov. 2009. UNESP - Universidade Estadual Paulista. http://dx.doi. org/10.5016/1980-6574.2010v16n1p01. 
DEEM, Rosemary; GILROY, Sarah. Physical Activity, Life-long Learning and Empowerment Situating Sport in Women's Leisure. Sport, Education And Society, [s.I.], v. 3, n. 1, p.89104, mar. 1998. Informa UK Limited. http://dx.doi.org/10.1080/1357332980030106.

DORNELLES, Priscila Gomes; FRAGA, Alex Branco. Aula mista versus aula separada? Uma questão de gênero recorrente na educação física escolar. Revista Brasileira de Docência, Ensino e Pesquisa em Educação Física, Cristalina, v. 1, n. 1, p.141-156, ago. 2009.

FERNANDES, Vera; MOURÃO, Ludmila. "Menina De Ouro" e a representação de feminilidades plurais. Movimento, Porto Alegre, v. 26, n. 3, p.1611-1629, dez. 2014. Trimestral. Disponível em: < http://seer.ufrgs.br/index.php/Movimento/article/ view/46151>. Acesso em: 14 maio 2018.

FERNANDES, Vera et al. Mulheres em combate: representações de feminilidades em lutadoras de Boxe e MMA. Revista da Educação Física/UEM, [s.I.], v. 26, n. 3, p.367376, 12 ago. 2015. Universidade Estadual de Maringá. http://dx.doi.org/10.4025/ reveducfis.v26i3.26009

FERRETTI, Marco Antônio de Carvalho. A formação da lutadora: estudo sobre mulheres que praticam modalidades de luta. 2011. 111 f. Dissertação (Mestrado) - Curso de Mestrado em Educação Física, EEFE-USP, Universidade de São Paulo, São Paulo, 2011. Disponível em: < http://www.teses.usp.br/teses/disponiveis/39/39134/tde-30052011084826/pt-br.php > . Acesso em: 14 maio 2018.

FOUCAULT, Michel. Vigiar e Punir. 40. ed. São Paulo: Vozes, 2013.

GOELLNER, Silvana Vilodre. Feminismos, mulheres e esportes: questões epistemológicas sobre o fazer historiográfico. Movimento, Porto Alegre, v. 13, n. 2, p.173-196, ago. 2007. Trimestral. Disponível em: < http://www.seer.ufrgs.br/Movimento/article/ viewArticle/3554>. Acesso em: 14 maio 2018.

. A educação dos corpos, dos gêneros e das sexualidades e o reconhecimento da diversidade. Cadernos de Formação RBCE, Porto Alegre, v. 1, n. 2, p.71-83, mar. 2010. Disponível em: <http://revista.cbce.org.br/index.php/cadernos/article/view/984>. Acesso em: 14 maio 2018.

JESUS, Mauro Louzada de; DEVIDE, Fabiano Pries. Educação física escolar, co-educação e gênero: mapeando representações de discentes. Movimento, Porto Alegre, v. 12, n. 3, p.123-140, dez. 2006. Trimestral. Disponível em: < http://www.seer.ufrgs.br/index. php/Movimento/article/view/2912/1548>. Acesso em: 14 maio 2018.

NASCIMENTO, Paulo Rogério Barbosa do; ALMEIDA, Luciano de. A tematização das lutas na Educação Física escolar: restrições e possibilidades. Movimento, Porto Alegre, v. 13, n. 3, p.91-110, dez. 2007. Trimestral. Disponível em: < http://seer.ufrgs.br/index. php/Movimento/article/view/3567/1968>. Acesso em: 14 maio 2018.

OLIVEIRA, Rogério Cruz de; DAOLIO, Jocimar. Na "periferia" da quadra: Educação Física, cultura e sociabilidade na escola. Pró-posições, Campinas, v. 25, n. 2, p.237254, ago. 2014. Disponível em: <www.scielo.br/pdf/pp/v25n2/13.pdf>. Acesso em: 14 maio 2018. 
RUFINO, Luiz Gustavo Bonatto; DARIDO, Suraya Cristina. O ensino das lutas nas aulas de Educação Física: análise da prática pedagógica à luz de especialistas. Revista da Educação Física/UEM, [s.I.], v. 26, n. 4, p.505-518, 25 out. 2015. Universidade Estadual de Maringá. http://dx.doi.org/10.4025/reveducfis.v26i4.26441. Disponível em: < http:// www.periodicos.uem.br/ojs/index.php/RevEducFis/article/view/26441/15525>. Acesso em: 14 maio 2018.

SALVINI, Leila.; MARCHI JÚNIOR, Wanderley. Mais do que uma "questão de peso": análise do conteúdo dos discursos de rivalidade entre as lutadoras de MMA. Movimento, Porto Alegre, v. 22, n. 3, p. 795-808, set. 2016. Trimestral. Disponível em < http://seer.ufrgs. br/index.php/Movimento/article/view/57916/38850 > . Acesso em: 14 maio 2018.

SCOTT, Joan. Gênero: uma categoria útil para os estudos históricos. Educação e Realidade, Porto Alegre, v. 15, n. 2, p.5-22, dez. 1990. Disponível em: < http://seer.ufrgs.br/index. php/educacaoerealidade/article/view/71721/40667>.

SILVA, Bruna Bárbara Proença Oliveira; CAVICHIOLLI, Fernando Renato; CAPRARO, André Mendes. Adesão e permanência de mulheres no boxe em Curitiba-PR. Motrivivência, [s.I.], v. 27, n. 45, p.124-137, 14 set. 2015. Universidade Federal de Santa Catarina (UFSC). http://dx.doi.org/10.5007/2175-8042.2015v27n45p124.

SO, Mauro Roberto; BETTI, Mauro. Lutas na Educação Física Escolar: relação entre conteúdo, pedagogia e currículo, Lecturas: Educación Fisica y Deportes, Buenos Aires, v. 17, n. 178, mar. 2013. Disponível em: < http://www.efdeportes.com/efd178/lutas-naeducacao-fisica-escolar.htm >. Acesso em: 14 maio 2018.

STAKE, Robert E. Case studies. In: DENZIN, Norman; LINCOLN, Yvonna. Strategies of qualitative inquiry. Thousand Oaks: Sage, 1998. Cap. 4. p. 86-109.

STENHOUSE, Lawrence. La investigación como base de la enseñanza. $2^{a}$ ed. Madri: Morata, 1993.

UCHOGA, Liane Aparecida Roveran; ALTMANN, Helena. Educação física escolar e relações de gênero: diferentes modos de participar e arriscar-se nos conteúdos de aula. Revista Brasileira de Ciências do Esporte, [s.I.], v. 38, n. 2, p.163-170, abr. 2016. Elsevier BV. http://dx.doi.org/10.1016/j.rbce.2015.11.006.

WACQUANT, L. Corpo e alma: notas etnográficas de um aprendiz de boxe. Rio de Janeiro: Relume Dumará, 2002.

WENETZ, Ileana; STIGGER, Marco Paulo. A construção do gênero no espaço escolar. Movimento. Porto Alegre, v.12, n.01, p.59-80, jan/abr. 2006. Trimestral.Disponível em < http://www.seer.ufrgs.br/index.php/Movimento/article/view/2891 > . Acesso em: 14 maio 2018.

Recebido em: Outubro/2017 Aprovado em: Fevereiro/2018 